\title{
ФОРМИРОВАНИЕ ЦИФРОВОЙ КОМПЕТЕНТНОСТИ ПЕДАГОГА КАК ЦЕЛЕВОЙ ОРИЕНТИР СИСТЕМЫ ПОДГОТОВКИ ПЕДАГОГИЧЕСКИХ КАДРОВ
}

\section{FORMATION OF DIGITAL COMPETENCE OF A TEACHER AS A TARGET REFERENCE POINT OF THE SYSTEM OF TRAINING OF PEDAGOGICAL PERSONNEL}

\section{O. Medvedeva}

Summary: The article is devoted to the actual problem of preparing future teachers for professional activity in the digital educational environment. The analysis of studies devoted to the increment of professional competencies of a teacher in the conditions of digitalization of education is presented. The essence and content characteristics of the digital competence of the teacher are determined. Digital competencies that ensure the successful professional activity of a teacher in new conditions are described. A comprehensive approach to the formation of digital competence of future teachers, ensuring their readiness to work in the conditions of digitalization of education, has been developed and theoretically justified.

Keywords: digital competence of a teacher, digital competence of a teacher, training of pedagogical personnel.

\section{Постановка проблемы}

$\Pi$ роисходящие в последнее время процессы цифровой трансформации общества и образования внесли существенные коррективы в содержание образовательного процесса, в формы и методы реализации образовательных событий. Это потребовало от педагогов освоение новых компетенций, среди которых основной является цифровая, которая определяет умение работать в условиях цифровой образовательной среды, умение адаптировать под специфику содержания своего предмета и особенности учеников цифровой материал, применять ИКТ-технологии в образовательном процессе. В то же время исследование готовности современных педагогов к использованию цифровых технологий в учебном процессе, проведенное специалистами аналитического центра НАФИ, показывает, что на настоящий момент «учителя школ не в полной мере используют цифровые решения для эффективного общения по работе, не достаточно активно создают собственные цифровые ресурсы, не вполне компетентны в вопросах создания и модификации цифровых учебных материалов и ресурсов, мало используют ресурсы сети Интернет и онлайн-сервисы в процессе учебных занятий

\author{
Медведева Ольга Анатольевна \\ К.п.н., доцент, ФГАОУВО «Севастопольский \\ государственный университет» \\ omedvedeva@mail.ru
}

Аннотация: Статья посвящена актуальной проблеме подготовки будущих педагогов к профессиональной деятельности в цифровой образовательной среде. Представлен анализ исследований, посвященных приращению профессиональных компетенций педагога в условиях цифровизации образования. Определяется сущность и содержательные характеристики цифровой компетентности педагога. Описаны цифровые компетенции, обеспечивающих успешную профессиональную деятельность педагога в новых условиях. Разработан и теоретически обоснован комплексный подход к формированию цифровой компетентности будущих педагогов, обеспечивающих их готовность к работе в условиях цифровизации образования.

Ключевые слова: цифровая компетентность педагога, цифровая компетенция педагога, подготовка педагогических кадров.

для работы учащихся в команде для совместной проектно-исследовательской деятельности, а также слабо используют цифровые инструменты для обеспечения учащихся обратной связью» [5, с. 239].

Таким образом, перед системой высшего образования стоят задачи по подготовке педагогических кадров, использующих в своей профессиональной деятельности современные цифровые технологии, способных и готовых к эффективной профессиональной деятельности в цифровой образовательной среде.

\section{Анализ последних исследований и публикаший}

Вопросы расширения состава компетенций педагога, изменений в профессиональной готовности педагога будущего, являются актуальным предметом педагогических обсуждений.

Характеризуя педагогов нового поколения, Е.А. Леонова, Л.С. Носова, А.А. Рузаков особо выделяют их способность адаптации к различным цифровым средам и технологиям обучения, а также способность прогнозировать грядущие изменения в постоянно меняющейся 
цифровой среде.

На цифровую компетентность педагога как определяющее начало создания высокотехнологичной цифровой образовательной среды школы указывают в своих исследованиях Т.А. Бороненко и В.С. Федотова [3]. По мнению ученых, учитель, как центральный объект цифровой школы, призван не только передавать предметные знания, решать задачи обучения, воспитания и развития, но и выполнять функции цифрового фасилитатора, являясь наставником обучающихся, ответственным за формирование их цифровой грамотности.

Способы формирования цифровой компетентности педагогов, их готовности к деятельности в цифровой образовательной среде рассматриваются в работах Н.П. Бурцева, Л.А. Григорович, Т.В. Добудько, Е.А. Качалиной, Э.В. Кулешовой, В.И. Пугач, О.Ю. Самойленко, К.А. Татаринова, Г.Г. Тенюковой, С.В. Титовой, И.А. Федоровой, Е.Г. Хрисановой, Н.П. Ячины.

Необходимость поиска инновационных способов формирования профессиональной готовности будущего учителя к «осознанному и методически грамотному владению современными средствами управления информацией и цифровыми инструментами» [6, с. 173] обосновывают в своих исследованиях Т.А. Куликова и Н.А. Поддубная.

Несмотря на значительное количество публикаций, посвященных вопросам цифровой компетентности педагогов, анализ тематических исследований авторов показал недостаточную проработку педагогических подходов к формированию цифровой компетентности будущих педагогов.

Цель нашего исследования состоит в разработке и теоретическом обосновании педагогических подходов к формированию цифровой компетентности будущих педагогов, обеспечивающих их готовность к профессиональной деятельности в условиях цифровизации образования.

\section{Основной материал исследования}

Разделяя точку зрения Е.И. Суховой и Д.М. Семичева, под цифровой компетентностью педагога мы понимаем его «способность использовать не только цифровые технологии, но и средства коммуникации и/или компьютерных сетей для доступа, управления, интегрирования, оценки и создания информации образовательного назначения в целях эффективного профессионального функционирования в существующей информационнообразовательной среде» [8, с. 101].

Формирование цифровой компетентности педаго- гов предполагает становление личности педагога, обладающей совокупностью особых ценностей, таких как: стремление к совершенствованию собственных знаний, умений и навыков, открытость новым технологиям и технологическому прогрессу, мотивация к деятельности в цифровой образовательной среде и формирование к ней положительного отношения, системой гибких, адаптивных и практико-ориентированных знаний, умений и навыков, способностей к анализу и отбору цифровых образовательных ресурсов, а также к их самостоятельной разработке [1].

Как отмечает в своих исследованиях доктор педагогических наук Т.Б. Гребенюк, педагог будущего должен отличаться от традиционного педагога способностями и умениями, специфичными для цифровой среды. В качестве цифровых компетенций, обеспечивающих успешную профессиональную деятельность педагога в условиях цифровой образовательной среды, ученый, опираясь на концепцию индивидуальности человека в соответствие с семью сферами психики, выделяет следующие компетенции.

1. Мотивационная сфера: стремление к педагогическому сотрудничеству при реализации цифровых технологий в обучении; стремление к профессиональному самосовершенствованию и самореализации, повышению педагогического мастерства в области цифровизации образования; направленность на инновационную деятельность, на реализацию цифровых технологий; стремление к получению удовлетворения от самого процесса и результата применения цифровых технологий; стремление к развитию индивидуальности учащихся в процессе цифрового обучения; мотивация достижений в профессиональной цифровой среде.

2. Эмоциональная сфера: адекватная педагогическая самооценка в условиях цифровизации образования; отсутствие тревожности и страха перед новыми требованиями к использованию цифровых технологий и ресурсов; эмоциональный интеллект (способность распознавать свои эмоции, понимать собственные намерения и желания, управлять своими эмоциями) в условиях цифровизации; способность распознавать эмоции обучающихся, их намерения, желания в условиях цифровизации и управлять ими.

3. Волевая сфера: настойчивость в достижении педагогической цели в цифровой среде; способность понимать собственные затруднения в реализации цифровых технологий и преодолевать их; способность защищать свои профессиональные взгляды в условиях цифровой среды (бойцовские качества); терпение и владение собой в условиях применения цифровых технологий при подготовке и проведении учебных занятий; умение при необ- 
ходимости преодолеть стереотипы и предубеждения в отношении цифровых технологий; способность мобилизовать свои индивидуальные, личностные и профессиональные ресурсы для овладения новыми цифровыми технологиями.

4. Предметно-практическая сфера: владение цифровыми технологиями; владение методикой преподавания учебной дисциплины с использованием цифровых технологий; способность работать в цифровой среде (определять целесообразность использования учащимися гаджетов на уроке, разрабатывать учебные задания для обращения к интернету, определять вариативность организации учебной деятельности с применением гаджетов и без них в урочное и внеурочное время, разрабатывать онлайн-курсы, общаться с учащимися и коллегами в дистанционном режиме, вести электронную обработку результатов учебной деятельности и др.); владение методическими приемами включения гаджетов в процессе создания и разрешения проблемных ситуаций на уроках; способность к самообучению в области цифровых технологий и ресурсов; компетентность во взаимодействии с коллегами, учащимися и их родителями по реализации цифровых технологий; умения осуществлять презентацию своих достижений в цифровой среде; умения работать над собой, заниматься самосовершенствованием в области цифровизации.

5. Интеллектуальная сфера: педагогическая эрудиция в области ИКТ и ресурсов, цифровая грамотность; педагогическое предвидение, прогнозирование, проектирование включения цифровых технологий в педагогическую и учебную деятельность; способность определять возможности девайсов в решении педагогических задач; креативность как способность к созиданию, а также действию в ситуации неопределенности и дефицита информации; способность увидеть главное для решения задачи в информационном потоке.

6. Сфера саморегуляции: умение осуществлять рефлексивные процессы (самонаблюдение, самоанализ, самооценку) в цифровой среде; способность осуществлять самоанализ в ситуациях выбора девайсов и цифровых технологи (основные направления адекватность цели обучения, соответствие учебным возможностям учащихся, наличию ресурсов); умение регулировать свою профессиональную деятельность с точки зрения цифровизации (следить за разумным обращением учащихся к гаджетам и при необходимости корректировать их действия); умения осознавать и регулировать свои психические состояния (эмоциональные, волевые, интеллектуальные и др.), возникающие в условиях реализации цифровых технологий; способность понимания необходимости овладения

\section{цифровыми технологиями}

7. Экзистенциальная сфера: наличие в качестве одной из важнейших целей педагогической деятельности формирование индивидуальности и личности учащегося в единстве (в частности, формирование осмысленного отношения школьника к использованию гаджетов и в учебной деятельности, и досуговой, и просвещенческой и др.); понимание цифровых технологий как средств развития индивидуальности человека в целом; понимание возможностей цифровизации обучения в развитии отдельных компонентов индивидуальности человека (каких конкретно); понимание возможностей цифровых технологий в воспитании учащегося; способность видеть, понимать и разъяснять учащимся и их родителям достоинства и недостатки цифровизации образования; способность занять профессиональную позицию в отношении цифровизации (какое место она должна занять в образовательном процессе?); педагогическое самосознание (сохранение и укрепление собственной позиции во взаимодействии с цифровым миром, осознание необходимости собственного выбора решения в цифровой проблемной ситуации); способность осознавать роль учителя в условиях цифровизации; способность оценить цифровизацию 1) как инновацию; 2) как средство повышения эффективности и качества образования; 3) как объективную необходимость [4].

Наивно предполагать, что с задачей формирования указанных цифровых компетенций может справиться только учебный курс по информатике, ориентированный в основном на изучение информационных и коммуникационных технологий и соответствующих ресурсов. Формирование указанных цифровых компетенций в педагогическом вузе требует комплексного подхода.

При проектировании основных образовательных программ по направлению «Педагогическое образование» необходимо учитывать следующее:

1. Содержание образовательной программы должно быть направлено на овладение студентами системой теоретических знаний, практических умений и навыков в области цифровых технологий, с целью развития универсальных и профессиональных компетенций в области обучения на разных уровнях образования, разработки и использования цифровых образовательных ресурсов для развития цифровой образовательной среды школы.

2. Структура и содержание образовательной программы должны обеспечивать междисциплинарные связи дисциплин информационно-технологического, методического, психолого- 
педагогического, предметно-содержательного циклов. Преемственность в развитии цифровых компетенций должна базироваться на взаимосвязи теоретического содержании дисциплин и практических заданий.

3. Реализация образовательной программы должна предполагать широкое использование цифровых образовательных ресурсов, как средств обучения, так и объекта изучения и исследования [2].

4. Для обеспечения целостности процесса формирования цифровой компетентности будущего педагога необходимо учесть аспекты цифровизации образования посредством интеграции модулей и создания связей между содержанием отдельных дисциплин [7].

В процессе профессиональной подготовки необходимо развивать у будущих педагогов готовность к решению следующих классов задач:

- методические - разработка учебно-методических материалов для сопровождения учебного процесса, электронных образовательных ресурсов, тестовых заданий; проведение уроков с применением средств информационных технологий, оценивание компетенций учащихся;

- организационно-управленческие - разработка и использование компонентов цифровой информационно-образовательной среды школы, связанных с организацией и управлением учебным процессом;

- проектные - использование метода проектов при обучении информатике и создании электронных образовательных ресурсов по различным предметам с учетом межпредметных связей;

- исследовательские - владение первоначальными умениями исследовательской работы в сфере образования, представление об основных способах презентации научных знаний [2].

Опираясь на исследования Н.Ю. Королевой, считаем, что формированию у будущих педагогов умений и навыков использования цифровых технологий в образовательном процессе будет способствовать включение в структуру основной образовательной программы следующих дисциплин (модулей):

1. «Информационно-правовая культура педагога», посвященную изучению правовых основ использования ресурсов сети Интернет, вопросов защиты персональных данных при работе в сети Интернет, организации профессионального взаимодействия и личного пространства в сети Интернет;

2. «Сетевые сервисы в образовании», включающую рассмотрение сетевых социальных сервисов Web 2.0 и облачных технологий, сервисов для хранения мультимедийной информации, сервисов для совместной работы и решения прикладных задач;
3. «Информационно-образовательные системы в обучении», рассматривающую основы информационно-образовательных систем обучения, вопросы педагогического проектирования электронных учебных курсов и их образовательного контента, подходы к контролю освоения учебного материала на учебном курсе;

4. «Оценивание результатов обучения на основе цифровых технологий», посвященную изучению альтернативных методов оценивания достижений обучаемых, рассмотрению современных технологий управления учебным процессом, а также тестовых технологий контроля качества знаний;

5. «Технологии электронного обучения», включающую изучение нормативно-правовых основ электронного обучения, дистанционных технологий обучения, технологии мобильного обучения виртуальной реальности в образовании;

6. «Социальное взаимодействие в виртуальном обществе», нацеленную на ознакомление с основами виртуального общества, мобильными технологиями, которые используются в виртуальном обществе [5].

Целесообразно в программы практик включать задания на оценку единой информационно-образовательной среды образовательной организации, формирование цифровых навыков и их развитие.

Необходимо отметить, что формированию цифровой компетентности будущих педагогов в процессе обучения в вузе способствует не только цифровое содержание учебной деятельности, но и «создание условий, требующих проявления и развития цифровых талантов и способностей (выражается в востребованности талантов и умений личности реализовать себя в новой среде); стремление к учебным целям при помощи цифровых технологий (свобода выбора обучения); проявление цифровой коммуникативной активности в студенческом и учебном сообществе (взаимодействие между студентами на основах цифровой грамотности, цифровой культуры); умение выявить правильные цифровые ориентиры учебной деятельности (цифровая упорядоченность процесса обучения)» [9, с. 324].

Формирование цифровой компетентности обучающихся по педагогическим направлениям предполагает развитие у них умений к построению профессионального взаимодействия в Интернет-пространстве, осуществлению информационного поиска, отбору и критической оценке профессионально важной информации, выстраиванию индивидуальной траектории непрерывного профессионального развития в открытом информационном пространстве.

Таким образом, современные тенденции цифрови- 
зации общества и образования поставили перед высшей школой задачу подготовки педагогов, осознанно и методически грамотно владеющими современными средствами управления информацией и цифровыми инструментами, способных адаптироваться к различным цифровым средам и технологиям обучения, обладающими способностями и умениями, специфичными для цифровой среды. Цифровая компетентность педагога определяется цифровыми компетенциями, характеризующими его индивидуальность в условиях деятельности в цифровой образовательной среде. Формирование цифровой компетентности будущих педагогов в условиях профессиональной подготовки в вузе должно носить комплексный характер и находить отражение в содержании и структуре основной образовательной программы, технологий и методик ее реализации, создании соответствующих организационнопедагогических условий.

\section{ЛИТЕРАТУРА}

1. Андреева Е.Е. Формирование цифровой компетенции будущих педагогов посредством педагогических хакатонов / Е.Е. Андреева, А.С. Новоселов // Вестник социально-гуманитарного образования и науки. - 2020. - № 2. - С. 4-10.

2. Баранова, Е.В. Развитие профессиональных компетенций бакалавров по направлению педагогического образования в области информатики в условиях цифрового образования / Е.В. Баранова, И.В. Симонова // Известия Российского государственного педагогического университета им. А.И. Герцена. 2018. - № 190. - С. 116-124.

3. Бороненко Т.А. Исследование цифровой компетентности педагогов в условиях цифровизации образовательной среды школы / Т.А. Бороненко, В.С. Федотова // Вестник Самарского университета. История, педагогика, филология. - 2021. - Т. 27, № 1. - C. 51-61. - D0I: 10.18287/2542-0445-2021-27-1-51-61.

4. Гребенюк Т.Б. Подготовка будущего педагога к цифровизации образования как педагогическая проблема / Т.Б. Гребенюк // Калининградский вестник образования. - 2020. - № 2 (6). - С. 20-27.

5. К Королева Н.Ю. Модель подготовки магистрантов педагогического образования к деятельности в виртуальной социально образовательной среде на основе развития цифровых компетенций / Н.Ю. Королева // Вестник Российского университета дружбы народов. Серия: Информатизация образования. - 2020. - T. 17, № 3. - C. 237-253. - D0I: 10.22363/2312-8631-2020-17-3-237-253.

6. Куликова Т.А. Формирование готовности будущего учителя к использованию технологий виртуальной и дополненной реальности в условиях цифровизации образования / Т.А. Куликова, Н.А. Поддубная // Вестник Северо-Кавказского федерального университета. - 2020. - № 3 (78). - C. 172-177. - D0I: 10.37493/2307-907Х.2020.3.20.

7. Носова Л.С. Модель цифровой культуры будущих педагогов в условиях цифровизации образования / Л.С. Носова, Е.А. Леонова, А.А. Рузаков // Вестник Южно-Уральского государственного гуманитарно-педагогического университета. - 2019. - № 4. - C. 134-154. - D0I: 10.25588/CSPU.2019.89.52.009.

8. Сухова Е.И. К вопросу о формировании цифровой компетентности педагогов дошкольного образования на современном этапе / Е.И. Сухова, Д.М. Семичев // Ученые записки Забайкальского государственного университета. - 2021. - T. 16, № 2. - C. 100-109. - D0I: 10.21209/2658-7114-2021-16-2-100-111.

9. Топилина Н.В. Цифровая компетентность бакалавров педагогического профиля / Н.В. Топилина, И.И. Топилина // Kant. - 2020. - № 2 (35). - С. 321-324. DOl: $10.24923 / 2222-243 X .2020-35.68$.

( ) Медведева Ольга Анатольевна (omedvedeva@mail.ru) 